\title{
Mechanical Pulmonary Valve Thrombosis: Recurrence and Response to Thrombolytic Therapy
}

\author{
Zahra Khajali ${ }^{1}$, Parham Sadeghipour ${ }^{2}$, Fatemeh Jorfi ${ }^{1}$, Maziar Gholampour ${ }^{1}$, Majid Maleki ${ }^{1}$, Sedigheh Saedi ${ }^{1}$, \\ Soheila Sadeghi ${ }^{1}$, Yasaman Khalilii ${ }^{1}$ and Ehsan Khalilipur ${ }^{2 *}$ \\ ${ }^{1}$ Rajaie cardiovascular medical and research center, Iran university of medical sciences, Tehran, Iran \\ ${ }^{2}$ Cardiovascular intervention research center, Rajaie cardiovascular medical and research center, Iran university of medical sciences, Tehran, Iran
}

Submission: May 07, 2021; Published: May 26, 2021

*Corresponding author: Ehsan Khalilipur, Cardiovascular intervention research center, Rajaie cardiovascular medical and research center, Iran university of medical sciences, Tehran, Iran

Abstract

Introduction: Prosthetic valve thrombosis (PVT) is a serious complication in the left-sided heart valve. However, in the right-side position, this complication may be completely asymptomatic or accompanied by only a few symptoms. Research on the prevalence of thrombosis in rightsided valves is still insufficient. We sought to retrospectively report our center's experience concerning PVT and its management outcomes.

Methods: We retrospectively evaluated thrombosis and recurrence in 118 patients with mechanical pulmonary valves during 19 years of patient admission in Rajaie Cardiovascular and Medical Research Center (2000-2019).

Results: We studied 186 episodes of malfunction due to thrombotic events in 118 patients with mechanical pulmonary valves. Thrombolytic therapy was applied in 181 episodes. Recurrence was reported in 44 patients, of whom 29 had 2 episodes of malfunction, 8 had 3 episodes, 5 had 4 episodes, and 2 had 5 episodes. The overall failure rate of thrombolytic therapy was $9.6 \%$ in all the episodes of malfunction secondary to PVT. Of the patients experiencing malfunction, $13.5 \%$ ultimately underwent redo pulmonary valve replacement (PVR). Among all the patients with mechanical valves $(\mathrm{n}=879)$, the rate of redo-PVR due to PVT was $2 \%$. Thrombolytic therapy failed in 13 episodes, partially succeeded in 17 , and completely succeeded in $151(83.4 \%)$.

Conclusion: Thrombolytic therapy is an effective treatment for PVT and its recurrence. The chances of re-thrombosis increase after the first episode of mechanical valve malfunction. It is, therefore, advisable to closely follow up patients with 1 episode of malfunction due to thrombosis, monitor their therapeutic international normalized ratio, and add 1 antiplatelet agent to hinder future episodes.

keywords: Mechanical pulmonary valve; Thrombolytic therapy; Prosthetic valve thrombosis; Subtherapeutic INR

\section{Introduction}

Prosthetic valve thrombosis (PVT) is a serious complication, particularly for left-sided heart valves; however, it is unprecedented within the aortic and mitral positions [1-3]. For the right-sided position, bioprosthetic valves are generally preferred to mechanical valves [4-6].

In tandem with medical advancements, the past 2 decades have witnessed a rise in the number of adults with congenital heart diseases (CHDs) and, thus, the rate of pulmonary valve implantation $[7,8]$. In the meantime, reports have emerged concerning the degeneration of bioprosthetic valves in the pulmonary position, leading to a higher interest in the use of mechanical valves in the right-sided position [9]. The occurrence of thrombosis within the tricuspid or pulmonary valve is not as alarming as that in the left-sided valve, with the event even having no symptoms in some patients. 10 It appears that thrombosis is far from uncommon in the right-sided valve; studies have reported a prevalence rate of between $12 \%$ and $15 \%$ [10,11]. Nonetheless, the literature still contains a dearth of data on thrombosis in the right-sided valve. According to the latest guideline of the American College of Cardiology/American Heart Association (ACC/AHA) vis-à-vis the management of patients with valvular diseases, PVT is managed by slow-infusion, low-dose fibrinolytic therapy [12].

We sought to evaluate all patients with mechanical pulmonary valves admitted for PVT to Rajaie Cardiovascular Medical and Research Center with a view to demonstrating the rates of recurrence and response to thrombolytic therapy. 


\section{Methods}

The present study is a case series of all patients with mechanical pulmonary valves admitted because of PVT to Rajaie Cardiovascular Medical and Research Center between 2000 and 2019. The patients' data, comprising demographic characteristics, clinical presentations, original congenital deformities, echocardiographic and catheterization laboratory information, the type of valve, the time elapsed from surgery, and the recurrence of thrombosis, were collected from a database of all admitted patients.

\section{Diagnostic Procedure}

In our center, all patients with mechanical pulmonary valves are visited every 6 months. If there is any abnormality in cardiac auscultation or any new symptom, the patient undergoes echocardiography. Additionally, every year after the first year of valve implantation, all patients with prosthetic heart valves undergo echocardiography. Those with increased prosthetic valve gradients on echocardiography or more-than-mild transvalvular regurgitation are referred for fluoroscopy. Pulmonary malfunction is confirmed by transthoracic echocardiography (TTE) and fluoroscopy. Any doubt regarding the final diagnosis is resolved by transesophageal echocardiography.

\section{Statistical Analysis}

The statistical analyses were conducted with SPSS, version 24.0 (SPSS Inc, Chicago), and the data were presented as mean values, standard deviations, and percentages. Between-group comparisons were done with the Mann-Whitney $U$ test for continuous variables and the $\chi 2$ test for categorical data. A P value lower than 0.05 was considered statistically significant. All the data were proved to be compatible with the medical ethical guidelines of Iran University of Medical Sciences.

\section{Results}

During a 19-year period, from 2000 to 2019, selected for the purposes of the present study, 1353 pulmonary valve replacement (PVR) procedures were performed and 879 patients (65\%) received a mechanical valve. A total of 186 episodes of malfunction happened in 118 patients, who accounted for $13.5 \%$ of all the patients. The study population, therefore, comprised 118 patients: 55 females (46.6\%) and 63 males (53.4\%), at a mean age of 29 years (10-55 y) and a mean age at surgery of 21 years. Of these patients, $84(71.1 \%)$ had a history of tetralogy of Fallot repair, $2(1.6 \%)$ had a history of congenitally corrected transposition of the great arteries with valve conduits, $2(1.6 \%)$ had a history of the Rastelli procedure, 6(5\%) had double-outlet right ventricles (RVs), and the rest $(7.9 \%)$ had a history of percutaneous transluminal pulmonary commissurotomy and surgical pulmonary valve commissurotomy. Two patients (1.6\%) were at 12 and 15 weeks of pregnancy. The mean interval between PVR and malfunction was 13 months (2-170 mon). Seventeen percent of these malfunction episodes happened within the first postoperative year and $42 \%$ in the first 2 years following PVR. The mechanical valves used were St Jude ( $n=74$ [62.7\%]), ON-X ( $n=9$ [7.6\%]), CarboMedics $(n=34$ [28.8\%]), and ATS ( $n=1[0.8 \%])$ (Table 1$)$.

Table 1: Clinical and demographic data of the study population.

\begin{tabular}{|c|c|c|}
\hline \multicolumn{3}{|c|}{ Demographic and Clinical Variables } \\
\hline \multicolumn{2}{|c|}{ Mean age } & $29 y$ \\
\hline \multicolumn{2}{|c|}{ Female } & $55(46.6 \%)$ \\
\hline \multicolumn{2}{|c|}{ Male } & $63(53.4 \%)$ \\
\hline \multicolumn{2}{|c|}{ Mean age at PVR } & $21 \mathrm{y}$ \\
\hline \multicolumn{2}{|c|}{ Time between PVR and the first episode of malfunction } & 13 mon \\
\hline Asymptomatic & & $46(38.9 \%)$ \\
\hline \multicolumn{2}{|c|}{ Symptomatic } & $71(60.1 \%)$ \\
\hline \multirow{4}{*}{ Valve type } & St Jude & 73 \\
\hline & CarboMedics & 34 \\
\hline & $\mathrm{ON}-\mathrm{X}$ & 9 \\
\hline & ATS & 1 \\
\hline
\end{tabular}

PVR: Pulmonary valve replacement.

Thirty-eight patients (32.2\%) were completely asymptomatic, and $56 \%$ of these asymptomatic patients declared that they visited the hospital earlier than their scheduled time because of diminished metallic heart sounds. Seventy-three patients (61.8\%) were symptomatic: $20 \%$ in the New York Heart Association functional class II or III and the rest in functional class I or II. In 12 patients (10.0\%), a definite diagnosis was confirmed by transesophageal echocardiography in addition to TTE and cine fluoroscopy. 


\section{Cinefluoroscopy Data}

Regarding malfunction episodes, 70 episodes (38\%) were due to 1 fixed leaflet, $89(48 \%)$ owing to 2 fixed leaflets, $9(5 \%)$ because of moderate restriction in both leaflets, and 18(9\%) secondary to severe restriction in both leaflets. In patients with recurrence, the form of involvement was not necessarily the same as the previous episode. Bileaflet restriction was reported in $45 \%$ of the patients suffering recurrence, single-leaflet restriction in 35\% $60 \%$ medial and $40 \%$ lateral), and severe bileaflet restriction in $20 \%$.

\section{Thrombolytic Regimen}

Seventy-seven episodes of malfunction (42.5\%) were treated with alteplase, 53 (29.2\%) with streptokinase, and 51 (28.1\%) with reteplase.

Streptokinase was given at a loading dose of 250000 IU in 30 minutes and then at a dose of 100000 IU per hour until hemodynamic improvement was achieved. Reteplase was administered at a STAT dose of $2 \times 10$ IU with a 30-minute interval. Alteplase was administered as a STAT dose of $10 \mathrm{mg}$, followed by a 90 mg infusion for 90 minutes in 31 episodes and 2 slow and ultraslow regimens in the remaining 46 episodes. Heparin infusion to obtain a partial thromboplastin time of 35 to 75 seconds was administered after thrombolytic treatment and continued for a few days to reach the target international normalized ratio (INR).

Warfarin was started on the day when the medical team was certain about the success of the treatment and continued to obtain an optimal INR. (An INR of 3-3.5 was the preferred ratio for mechanical pulmonary valves) [12].

If the result of the first dose was not satisfactory, the streptokinase regimen was continued for a maximum of 4 days, reteplase at a maximum dose of $40 \mathrm{IU}$, and alteplase at a maximum dose of $125 \mathrm{mg}$.

\section{Defining Response to Thrombolytic Therapy}

A complete response was considered if echocardiography showed a significant reduction in TTE transvalvular gradients by comparison with baseline, indicating the elimination of transvalvular regurgitation, in addition to normal leaflet motion on fluoroscopy and alleviation of symptoms in the absence of major complications. A partial response was defined as an incomplete restoration of the valve function, characterized by the restricted motion of the valve leaflets. The absence of a hemodynamic and clinical response after the target dose of thrombolytic was considered a failed response.

\section{Recurrent Episodes}

Of the 118 patients with PVT, 74 patients (68\%) experienced only 1 episode of malfunction, with the remaining 44 patients (38\%) suffering the recurrence of thrombotic events. Twentynine patients $(24.5 \%)$ experienced 2 episodes of malfunction, 8 patients (6.7\%) 3 episodes, 5 patients (4.2\%) 4 episodes, and 2 patients $(1.6 \%) 5$ episodes. Of the 44 patients who had more than 1 episode of malfunction, 20 (45\%) were female. The mean interval between the first episode of malfunction and recurrence was 14 months (2-70 mon). The prevalence of malfunction was $13 \%$ for the first time, $25 \%$ for the second time, $27.5 \%$ for the third time, and $40 \%$ and for the fourth and fifth times. Eighteen patients with more than 1 episode of malfunction had the CarboMedics valve (40.9\%), 1 had the $\mathrm{ON}-\mathrm{X}$ valve, and 25 had the St Jude valve (56.8\%) (Table 2).

Table 2: Clinical characteristics of the patients with and without recurrence.

\begin{tabular}{|c|c|c|}
\hline Clinical Variables & $\begin{array}{c}\text { Patients Without Recurrence (To- } \\
\text { tal=74) }\end{array}$ & $\begin{array}{c}\text { Patients With Recurrence (To- } \\
\text { tal=44) }\end{array}$ \\
\hline Mean age & $31.5 \mathrm{y}$ & $27.5 \mathrm{y}$ \\
\hline Female & $35(47.2 \%)$ & $20(45.4 \%)$ \\
\hline Male & $39(52.7 \%)$ & $24(54.5 \%)$ \\
\hline $\begin{array}{c}\text { Mean time between the first episode and the second } \\
\text { episode of malfunction }\end{array}$ & - & 14 months \\
\hline Valve Type & & $25(56.8 \%)$ \\
\hline St Jude & $49(66.2 \%)$ & $18(40.9 \%)$ \\
\hline CarboMedics & $14(18.9 \%)$ & 1 \\
\hline Other valves & $11(14.8 \%)$ & \\
\hline
\end{tabular}

\section{Echocardiographic Data}

The rate of the fractional area change (FAC) of the RV among all the patients was $23 \%$, and severe RV systolic dysfunction (FAC $<17 \%$ ) was detected in $10 \%$. Severe left ventricular (LV) systolic dysfunction (LV ejection fraction $<35 \%$ ) was reported in $8 \%$ of the patients and severe RV enlargement (RV end-diastolic diameter $>5 \mathrm{~cm}$ in the base of the RV) in $45 \%$.
Among the patients with recurrence, the rate of RVFAC was $22 \%$. Severe LV systolic dysfunction was reported in 8 patients (18\%) and severe RV enlargement in 55\% (Table 3).

\section{Primary Outcomes}

The study population comprised 118 patients with 186 episodes of malfunction due to PVT. Thrombolytic therapy was 
tried in all the 186 episodes, with a failure rate of $9.6 \%$. Of the patients experiencing malfunction, 16 patients (13.5\%) ultimately needed redo-PVR: 12 patients received bioprostheses and 4 patients mechanical prosthetic valves. Among all the patients with mechanical valves $(n=879)$, the rate of redo-PVR secondary to PVT was $2 \%$. A complete response to thrombolytic therapy was reported in 151 cases (83.4\%), a failed response in 13 (6.9\%), and a partial response in 17 (9.1\%). In the first episode of malfunction, there were 7 failed responses (6\%) and 8 partial responses $(7 \%)$. The success rate was $87 \%$ for the first episode, while the rate of a complete response in the next episodes was $77 \%$ (Table 3). These data showed a remarkable response to thrombolytic therapy in the first and recurrent episodes of malfunction. The success rate was $85 \%$ for alteplase, $83 \%$ for streptokinase, and $80 \%$ for reteplase; however, there was no statistical difference either between these 3 regimens of thrombolytic therapy or between the different infusion regimens of alteplase. ASA was administered to $78 \%$ of the patients with thrombosis. Nonetheless, following thrombolytic therapy, $94 \%$ of the patients were given ASA (81 mg daily) with warfarin to prevent future acute thrombotic events. Minor bleeding was reported in 8 cases from all the 186 episodes (4.3\%): streptokinase was administered for 6 of these cases $(75 \%)$ and reteplase and alteplase each for 1 of these cases. No patient had major bleeding at the index hospitalization. One patient following the third malfunction underwent redo surgery, but he passed away because of surgical complications. There was no significant association between the incidence of recurrence of mechanical valve thrombosis and gender $(\mathrm{P}=0.11)$, the prosthetic valve size $(24.6 \mathrm{~mm}$ in all the mechanical valves vs $24.4 \mathrm{~mm}$ in the patients with valvular thrombosis; $\mathrm{P}=0.26$ ), the type of prosthetic valve $(\mathrm{P}=)$, and echocardiographic data. Between all thrombolytic regimen there was seen no significant difference in complete and partial responses.

Table 3: Echocardiographic data in the patients with and without recurrence.

\begin{tabular}{|c|c|c|c|}
\hline Echocardiographic Parameters & Without Recurrence & With Recurrence & P value \\
\hline RVFAC $(24 \%-32 \%, 17-24 \%,<17 \%)$ & $30(40 \%), 33(44 \%), 7(9 \%)$ & $17(38 \%), 20(45 \%), 5(11 \%)$ & 0.6 \\
\hline RVEDD $(>5 \mathrm{~cm}, 4-5 \mathrm{~cm},<4 \mathrm{~cm})$ & $29(39 \%), 38(51 \%), 7(10 \%)$ & $24(54 \%), 18(40 \%), 2(4 \%)$ & 0.2 \\
\hline LVEF $(35 \%-45 \%,<35 \%)$ & $55(74 \%), 5(6 \%)$ & $36(80 \%), 4(8 \%)$ & 0.17 \\
\hline
\end{tabular}

RVFAC: Right ventricular fractional area change; RVEDD: Right ventricular end-diastolic diameter; LVEF: Left ventricular ejection fraction.

Table 4: Thrombolytic response to the 3 types of regimen.

\begin{tabular}{|c|c|c|c|c|c|c|c|}
\hline \multirow{2}{*}{\multicolumn{2}{|c|}{$\begin{array}{c}\text { Thrombolytic Regimen } \\
\text { Number }\end{array}$}} & Episode 1 & Episode 2 & Episode 3 & Episode 4 & Episode 5 & Total \\
\hline & & Number & Number & Number & Number & Number & \\
\hline \multirow{3}{*}{ Streptokinase } & complete & $36(85 \%)$ & $9(70 \%)$ & $1(50 \%)$ & & & 46 \\
\hline & partial & $3(7.5 \%)$ & $2(15 \%)$ & $1(50 \%)$ & & & 6 \\
\hline & failed & $3(7.5 \%)$ & $2(15 \%)$ & & & & 5 \\
\hline \multirow{3}{*}{ Reteplase } & complete & $22(84 \%)$ & $16(84 \%)$ & $4(66 \%)$ & & & 42 \\
\hline & partial & $2(8 \%)$ & $2(10 \%)$ & $1(17 \%)$ & & & 5 \\
\hline & failed & $2(8 \%)$ & $1(6 \%)$ & $1(17 \%)$ & & & 4 \\
\hline \multirow{4}{*}{ Alteplase } & complete & 45 (90\%) & $11(82 \%)$ & $4(66 \%)$ & $5(82 \%)$ & $2(100 \%)$ & 67 \\
\hline & partial & $3(6 \%)$ & $1(9 \%)$ & $1(17 \%)$ & $1(18 \%)$ & & 6 \\
\hline & failed & $2(4 \%)$ & $1(9 \%)$ & $1(17 \%)$ & 0 & & 4 \\
\hline & Total & 118 & 41 & 14 & 6 & 2 & 186 \\
\hline
\end{tabular}

\section{Subtherapeutic INR}

Based on the latest ACC/AHA guideline, the preferred INR for mechanical valves in the pulmonary position is 3 to 3.5 [12]. In our study, the INR was below 3 in $90 \%$ of the patients with the first episode of malfunction, below 3 in $88 \%$ of the patients with the second episode ( $95 \%$ had an INR $<3.5$ ), below 3 in $25 \%$ of the patients with the third recurrent episode (87.5\% had an INR<3.5), and below 3.5 in $80 \%$ of the patients with the fourth episode. The
INR was below 2 in $72 \%$ in the first episode, below 2 in $60 \%$ in the second episode, and below 2 in $10 \%$ in the third episode of malfunction. The optimal INR on admission was reported in 12 patients $(10 \%)$.

The time in the therapeutic range (TTR) was assessed via the Rosendaal method. Predictably, $60 \%$ of the study population had a TTR value below $55 \%$ and only 5 patients (in the 118 patients [4.2\%]) had an appropriate TTR value. 


\section{Thrombolytic Therapy in Pregnancy}

In this large case-series study, 2 pregnant women at 12 and 18 weeks of gestation were admitted because of PVT. Both were given $25 \mathrm{mg}$ of an alteplase infusion in 6 hours, which yielded a complete therapeutic response and without any bleeding complications.

\section{Discussion}

Thanks to progressive advancements in CHD surgery, many patients with tetralogy of Fallot, double-outlet RVs, pulmonary stenosis, and other CHDs associated with pulmonary stenosis undergo surgery in the neonatal or infantile period $[2,10]$. Fortunately, improved surgical techniques for sparing the pulmonary valve and annulus have significantly diminished the prevalence of pulmonary valve insufficiency [7]. Nevertheless, for patients who had corrective surgery 2 to 3 decades ago, the rate of pulmonary valve insufficiency is still high, with a significant number of these patients requiring PVR. Because patients who need PVR are younger adults, the long-term durability of the bioprosthesis has yet to be established, [3,6,13-16] which has increased the use of mechanical valves in some developing countries. 20 During a 19-year period, our center recorded 1353 PVR procedures, in 879 (65\%) of which mechanical valves were implanted.

While the PVT incidence is higher for right-sided mechanical valves than left-sided mechanical valves, $[5,17,15,18]$ there is a paucity of large-scale studies regarding the prevalence of rightsided PVT. A previous study on thrombolytic therapy reported a prevalence rate of $15 \%$ for right-sided PVT for all mechanical prostheses [19]. We assessed our center's 19 years of experience concerning the use of mechanical valves in PVR. The records showed 1353 PVR procedures and the use of mechanical valves in 879 patients (65\%), of whom 118 patients $(13.5 \%)$ developed PVT. Unlike patients with left-sided PVT, those with right-sided PVT reported mild symptoms. A significant percentage of our patients (38\%) with PVT had no symptoms; consequently, we needed a high index of suspicion for PVT and careful examinations to establish the diagnosis $[6,17,18,20]$. A decline in metallic heart sounds as reported by patients proved invaluable to our diagnosis. Indeed, a reduction in the muffled metallic sound should serve as a warning to patients with mechanical valves.

The efficacy of thrombolytic therapy has been reported in many studies $[21,17,15,22-26]$. Thrombolysis is a Class I AHA and a Class IIa European Society of Cardiology (ESC) guideline recommendation for left-sided thrombosis $[11,12,27,28]$. Our study showed a high efficacy rate for thrombolytic therapy $(>80 \%$ ) for PVT, $[12,17,24,29-33]$ with the efficiency boosted further by longer durations of thrombolytic drug administration. For streptokinase, the response rate to thrombolytic was $30 \%$ on the first day of infusion and it reached $80 \%$ on the third day. For alteplase, the rate of response was $70 \%$ at the first dose and it reached $85 \%$ with the continuation of the infusion. No study has yet compared efficacy between different thrombolytic drugs for right-sided PVT. In this large case-series study, we demonstrated no statistically significant difference between streptokinase, reteplase, and alteplase with different regimens, and these 3 thrombolytic drugs were equally effective in the treatment of right-sided PVT.

A salient strength of the current study is our evaluation of patients with recurrent thrombosis. Recurrent PVT has been reported in between $11 \%$ and $18 \%$ of patients with left-sided valve thrombosis, [21,24,34] and some studies have reported a poor response to treatment, especially in redo surgery [24]. Different small studies have shown successful thrombolytic therapy in recurrent thrombosis. In our investigation, $25 \%$ of the study population had recurrent thrombotic events and we treated $90 \%$ again with thrombolytic therapy and achieved a $77 \%$ success rate. Although the response relative to the first episode was low, it was a significant response and thrombolytic therapy could be performed safely for recurrent episodes. We tried a low-dose, slow-infusion regimen of thrombolytic therapy in 2 pregnant patients with complete success and with no complications in keeping with the recommendations of Özkan et al. [35].

In our study, the major trigger for and the only contributing factor to valve thrombosis was a low INR, which also played a definite role in recurrent episodes. In our recurrent PVT cases, the INR was reported to range between 3 and 3.5. Accordingly, in a patient with a history of recurrence, the INR should be monitored at a level exceeding 3.5 with an increased risk of bleeding. The prevention of PVT requires regular and accurate INR monitoring. In accordance with the 2017 ACC/AHA guideline, recommending an antiplatelet regimen for all mechanical heart valves, for our patients without any additional bleeding risk, we also prescribed 1 antiplatelet agent, which was mostly ASA (81 mg daily) after the first episode to prevent future valve thrombosis [36].

\section{Conclusion}

In this large case-series study, patients with mechanical prostheses in the pulmonary position demonstrated thrombosis, with recurrence being more prevalent in right-sided prosthetic heart valves. Fortunately, thrombolytic therapy had a high success rate, regardless of the kind of thrombolytic drug, and a low complication rate in treating thrombosed mechanical pulmonary prostheses as well as recurrent events. PVT was rare with therapeutic INR, and the most common cause of PVT was poor drug compliance or inadequate anticoagulant therapy. Thus, tight control of INR is necessary to prevent this complication. Our study findings demonstrated that mechanical PVR could be a choice for selected patients with good compliance with anticoagulation therapy. The major concern regarding PVT can be resolved by accurate patient selection and careful INR monitoring.

Limitations: The retrospective nature of this case-series should be borne in mind in the interpretation of the results. 
Prospective long-term studies should be undertaken to overcome this obstacle.

\section{Conflict of Interest: None declared.}

\section{References}

1. Balasundaram RP, Karthikeyan G, Kothari SS, Talwar KK, Venugopal P (2005) Fibrinolytic treatment for recurrent left-sided prosthetic valve thrombosis. Heart 91(6): 821822.

2. Deviri E, Sareli P, Wisenbaugh T, Cronje SL (1991) Obstruction of mechanical heart valve prosthesis clinical aspects and surgical management. J Am Coll Cardiol 17(3): 646-650.

3. Horstkotte D, Burckardt D (1995) Prosthetic valve thrombosis. J Heart Valve Dis 4(2): 141-153.

4. Bove EL, Kavey RE, Byrum CJ, Sondheimer HM, Blackman MS, et al. (1985) Improved right ventricular function following late pulmonary valve replacement for residual pulmonary insufficiency or stenosis. J Thorac Cardiovasc Surg 90(1): 50-55.

5. Dos L, Munoz-Guijosa C, Mendez AB, Ginel A, Montiel J, et al. (2011) Long-term outcome of the mechanical valve prosthesis in the pulmonary position. Int J Cardiol 150(2): 173-176.

6. Miyamura H, Kanazawva H, Hayashi J, Eguchi S (1987) Thromhosed St. Jude Medical valve prosthesis in the right side of the heart in patients with tetralogy of Fallot. J Thorac Cardiovasc Surg 94(1):148-150.

7. Thorburn CW, Morgan JJ, Shanahan MX, Chang VP (1983) Long-term results of tricuspid valve replacement and the problem of prosthetic valve thrombosis. Am J Cardiol 51(7): 1128-1132.

8. Simpson D, Siddiqui MA, Scott LJ, Hilleman DE (2007) Spotlight on reteplase in thrombotic occlusive disorders. BioDrugs 21(1): 65-68.

9. Khajali Z, Mohammadzadeh S, Maleki M, Peighambari MM, et al. (2015) Fibrinolytic therapy for mechanical pulmonary valve thrombosis. Pediatric cardiology 36(1): 171-176.

10. Burger W, Kneissl G-D, Hartmann A, Bauersachs R, Doring V, et al (1997) Successful thrombolysis after prosthetic pulmonary valve obstruction under aspirin monotherapy. Ann Thorac Surg 64(1): 255-257.

11. Roudaut R, Lafitte S, Roudaut MF, Courtauld C, Perron JM, et al. (2003) Fibrinolysis of mechanical prosthetic valve thrombosis: a single-center study of 127 cases. J Am Coll Cardiol 41(4): 653-658.

12. Writing Committee Members, Otto CM, Nishimura RA, Bonow RO, Carabello BA, Erwin JP 3rd, et al. (2021) 2020 ACC/AHA Guideline for the Management of Patients With Valvular Heart Disease: Executive Summary: A Report of the American College of Cardiology/American Heart Association Joint Committee on Clinical Practice Guidelines. J Am Coll Cardiol 77(4): 450-500.

13. Boni L, García E, Galletti L, Pérez A, Herrera D, et al. (2009) Current strategies in tetralogy of Fallot repair: pulmonary valve sparing and evolution of right ventricle/left ventricle pressures ratio. European Journal of Cardio-Thoracic Surgery 35(5): 885-890.

14. Fleming WH, Sarafian LB, Moulton AL, Robinson LA, Kugler JD (1989) Valve replacement in the right side of the heart in children: long-term follow-up. Ann Thorac Surg 48(3): 404-408.

15. Hammermeister K, Sethi GK, Henderson WG, Grover FL, Oprian C, et al. (2000) Outcomes 15 years after valve replacement with a mechanical versus a bioprosthetic valve: final report of the veterans affairs randomized trial. JACC 36(4): 1152-1158.

16. Shapira Y, Vaturi M, Hasdai D, Battler A, Sagie A (2003) The safety and efficacy of repeated courses of tissue-type plasminogen activator in patients with stuck mitral valves who did not fully respond to the initial thrombolytic course. J Thromb Haemost 1(4): 725-728.

17. Stulak JM, Dearani JA, Burkhart HM, Connolly HM, Warnes CA, et al. (2010) The increasing use of mechanical pulmonary valve replacement over a 40-year period. Ann Thorac Surg 90(6): 2009-2015.

18. Marti V, Subirana MT, Baillester M, Obrador D, Aug JM, et al (1992) Successful thrombolytic therapy for prosthetic pulmonary valve thromilbosis evaluated by Doppler echocardiography. Am Heart J 123(4 Pt 1): 1065-1067.

19. Cáceres-Lóriga FM, Pérez-López H, Morlans-Hernández K, FacundoSánchez H, Santos-Gracia J, et al. (2006) Thrombolysis as first choice therapy in prosthetic heart valve thrombosis. A study of 68 patients. J Thromb Thrombolysis 21(2): 185-190.

20. Edmunds LH (1982) Thromboembolic complications of current cardiac valvular prosthesis. Ann Thorac Surg 34(1): 96-106.

21. Kontos GH, Schaff HV, Orszulak TA, Puga FJ, Pluth JR, et al (1989) Thrombotic obstruction of disc valves: clinical recognition and surgical management. Ann Thorac Surg 48(1): 60-65.

22. Hurrell G, Schaff HV, Tajik J (1996) Thrombolytic therapy for obstruction of mechanical prosthetic valves. Mayo Clin Proc 71(6): 605-613.

23. Okita Y, Miki S, Kusuhara K, Ueda Y, Tahata T, et al. (1992) Replacement of a thrombosed St. Jude Medical prosthesis in pulmonary position after repeated thrombolytic therapy. Thorac Cardiovasc Surg 40(2): 99-101.

24. Schultz SC, Ambra PD (2003) Reteplase thrombolysis for treatment of mechanical valve thrombosis. J Invasive Cardiol 15(3): 156.

25. Nishimura RA, Otto CM, Bonow RO, Carabello BA, Erwin JP, 3rd, et al. (2014) 2014 AHA/ACC Guideline for the Management of Patients With Valvular Heart Disease: executive summary: a report of the American College of Cardiology/American Heart Association Task Force on Practice Guidelines. Circulation 129(23): 2440-2492.

26. Nawale JM, Chaurasia AS, Nalawade DD, Abdagire N (2018) Clinical Profile of Patients with Prosthetic Valve Thrombosis Treated with Fibrinolysis. J Pract Cardiovasc Sci 4: 109-115.

27. Pigula FA, Khalil PN, Mayer JE, del Nido PJ, Jonas RA (1999) Repair of Tetralogy of Fallot in Neonates and Young Infants. Circulation 100(19 Suppl): II157-II161.

28. Garg J, Palaniswamy C, Pinnamaneni S, Sarungbam J, Jain D (2016) Prosthetic Valve Thrombosis: Diagnosis and Management. Am J Ther 23(1): e252-e255.

29. Mehmet Özkan, Beytullah Çakal, Süleyman Karakoyun, Ozan Mustafa Gürsoy, Cihan Çevik, et al. (2013) Thrombolytic Therapy for the Treatment of Prosthetic Heart Valve Thrombosis in Pregnancy With Low-Dose, Slow Infusion of Tissue-Type Plasminogen Activator. Circulation 128(5): 532-540.

30. Shapira Y, Vaturi M, Hasdai D, Battler A, Sagie A (2003) The safety and efficacy of repeated courses of tissue-type plasminogen activator in patients with stuck mitral valves who did not fully respond to the initial thrombolytic course. J Thromb Haemost 1(4): 725-728.

31. Roudaut R, Labbe T, Lorient-Roudaut MF, Gosse P, Baudet E, et al. (1992) Mechanical cardiac valve thrombosis: is fibrinolysis justified? Circulation 86(5 Suppl): II8-II15.

32. Vitale N, Renzulli A, Cerasuolo F, Caruso A, Festa M, et al. (1994) Prosthetic valve obstruction: thrombolysis versus operation. Ann Thorac Surg 57(2): 365-370.

33. Sadeghpour A, Javani B, Peighambari M, Kyavar M, Khajali Z (2012) Mid-term follow-up of pulmonary valve bioprostheses in adults with congenital heart disease. Anadolu Kardiyol Derg 12(5): 434-436. 
34. Joint Task Force on the Management of Valvular Heart Disease of the European Society of Cardiology (ESC), European Association for CardioThoracic Surgery (EACTS), Vahanian A, Alfieri O, Andreotti F, Antunes MJ, Barón-Esquivias G, et al. Guidelines on the management of valvular heart disease (version 2012). Eur Heart J 33(19): 24512496.

35. Mehmet Özkan, Beytullah Çakal, Süleyman Karakoyun, Ozan Mustafa Gürsoy, Cihan Cevik, et al. (2013) Thrombolytic Therapy for the Treatment of Prosthetic Heart Valve Thrombosis in Pregnancy With Low-Dose, Slow Infusion of Tissue-Type Plasminogen Activator Circulation 128(5): 532-540.
36. Ilbawi MN, Idriss FS, DeLeon SY, Muster AJ, Duffy CE, et al (1987) Valve replacement in children: guidelines for selection of prosthesis and timing of surgical intervention. Ann Thorac Surg 44(4): 398-403.

\section{Your next submission with Juniper Publishers will reach you the below assets}

- Quality Editorial service

- Swift Peer Review

- Reprints availability

- E-prints Service

- Manuscript Podcast for convenient understanding

- Global attainment for your research

- Manuscript accessibility in different formats

(Pdf, E-pub, Full Text, Audio)

- Unceasing customer service

Track the below URL for one-step submission https://juniperpublishers.com/online-submission.php 